\title{
Particle Swarm Based Optimization of Power Losses in Network Using STATCOM
}

\author{
V. Tuzikova, Z. Müller, J. Švec, V. Valouch and J. Tlustý \\ Department of Electric Power Engineering \\ Faculty of Electrical Engineering, CTU in Prague \\ Technická 2, 16627 Prague, Czech Republic \\ Phone: +420 2 2435 2143, E-mail: tlusty@fel.cvut.cz
}

\begin{abstract}
The main goal of this paper is to define the best location for the STATCOM compensator in order to minimize active power losses in the grid, using Particle Swarm Optimization algorithm.
\end{abstract}

\section{Key words}

Electric power system, Simulation, Power losses, STATCOM, Particle swarm optimization.

\section{Introduction}

The cost of transmission lines tower and conductors and power losses during the operation often limit the available transmission capacity [1]. There are many cases where economic energy delivery is constrained by the transmission capacity. In a deregulated environment, an effective electric grid is vital to provide reliable electric energy supplies to customers at all voltage levels [2].

Recently, increased demands on electric energy transmission and the need to provide access to generating companies and customers have created tendencies toward lower security and reduced quality of supply. The FACTS technology is promising to reduce some of these difficulties by enabling utilities to get more performance from their transmission facilities and to enhance grid reliability [3]. An optimal power flow (OPF) approach was proposed to minimize network energy losses by means of reactive power control using FACTS devices while satisfying the network operating voltage and thermal limits.

The idea of optimal power flow was introduced in the early $1960 \mathrm{~s}$ as an extension of conventional economic dispatch to determine the optimal settings for control variables with respect to various constraints. The term OPF is used as a general name for a large series of network optimization problems. Many different approaches have been proposed to solve OPF problems.
The general OPF problem is formulated to minimize the general objective function $\mathrm{F}(\mathrm{x}, \mathrm{u})$ while satisfying constraints $\mathrm{g}(\mathrm{x}, \mathrm{u})=0$ and/or $\mathrm{h}(\mathrm{x}, \mathrm{u}) \leq 0$ where $\mathrm{g}(\mathrm{x}, \mathrm{u})$ represents nonlinear equality constraints (power flow equations) and $\mathrm{h}(\mathrm{x}, \mathrm{u})$ is nonlinear inequality constraints on the vectors $x$ and $u$. The vector $x$ contains the dependent variables including bus voltage magnitudes and phase angles and the reactive power output of generators designed for bus voltage control. The vector $\mathrm{x}$ also includes fixed parameters, such as reference bus angles, uncontrolled active and reactive powers for generators and loads, fixed impedances, line parameters, etc. The active power losses minimization is usually required when cost minimization is the main goal.

The following assumptions are usually made to formulate the losses objective:

- Losses minimization is made following the cost minimization. Hence the active power generations excluding the slack bus generation are held at their optimal values.

- Generator bus voltages and transformer tap ratios are used as control state variables. Shunt reactances and phase-shifting transformers angles are held at their rated values.

- Transformer tap ratios are treated as continuous variables during the optimization. Afterwards they are adjusted to the nearest tap position and reiterated.

- Current flows are controlled approximately, using restrictions on the real and imaginary components of the complex voltage drop across the lines.

Contingency constraints are neglected. Mathematical description of the objective function for active power losses minimization in the power system is given by the sum of active power losses in all branches and transformers.

There are many optimization algorithms with many techniques appropriate only for certain type of problems. Thus, it is important to be able to recognize the task characteristics in order to identify an appropriate solution method. In each task class, there are different 
minimization methods distinguished in computational requirements, convergence properties, etc. Optimization problems are classified according to the mathematical characteristics of the objective function, the constraints, and the control variables. Probably the most important characteristic is the nature of the objective function.

Particle Swarm Optimization (PSO) is an optimization method based on the principles of natural selection and genetics. This method can look for more solutions simultaneously. PSO generates random initial particles in the first step and then it applies velocity vectors to update the particles until a process stop condition is satisfied. It requires the test function calculation to determine how a reached solution is good [4]. PSO has been used for solving many power engineering tasks, e.g. UPFC placement and its parameters optimization for possible load increasing, distributed generation placement and sizing optimization with respect to customers' electricity cost or economic dispatch [5], [6], [7].

Particle swarm optimization is similar to a genetic algorithm in a way that the system is initialized with a population of random solutions. However, each potential solution (called a particle) obtains a random velocity and then it moves through the problem n-dimensional space. PSO has been found to be very efficient in solving a wide range of engineering problems. It can be implemented very simply and solve the tasks very quickly. During several past years a great effort has been devoted to the research of the optimal STATCOM design and its appropriate placement by means of the PSO strategy [8]-[11]. A good review of modern optimization techniques useable in the field is presented in [12]. In our paper we use the PSO strategy to optimize active power losses in a power system by the STATCOM optimal placement.

\section{Problem formulation}

Electric power losses in transmission and distribution systems depend mainly on the system configuration, elements (power lines, transformers) parameters and a current operational state. The active power losses reduce the efficiency of energy transmission to customers and increase the operational costs. Therefore they are highly monitored, analyzed and minimized. As for elements models, the losses are caused mainly du to series resistances (by flowing currents), partially by shunt resistances (by operational voltage).

Considering only the series resistances, the total active power losses in a distribution system can be calculated as follows

$$
\mathrm{P}_{\text {loss }}=\sum_{\mathrm{i}=1}^{\mathrm{n}} \mathrm{R}_{\mathrm{i}} \mathrm{I}_{\mathrm{i}}^{2}
$$

where $\mathrm{n}$ is the total number of branches in the system, $I_{i}$ is the current flowing in branch $\mathrm{i}, \mathrm{R}_{\mathrm{i}}$ is the resistance and of branch $\mathrm{i}$. The distribution network ended by consumers is the terminal stage of power system. The problems that may be found in the distribution network affect both consumers and utilities. One of these problems is the voltage drop that must be reduced to keep the voltages at load points within standard limits. The voltage drop problem may arise when lateral radial feeders with a long distance or feeding large loads are used. Thus the voltage at different nodes of the system must be controlled. The voltage control means generally reactive power control. Consequently, controlling the reactive power and the node voltages result in a reduction of power loss. To enhance the voltage and to control the reactive power, the distribution systems are equipped with many voltage controlling devices.

The STATCOM (Static Compensator) is a compensator based on a VSC (Voltage Source Converter) design, utilizing IGBT (Insulated Gate Bipolar Transistor) as reliable high speed switching elements and a control concept based on pulse-width modulation (Fig. 1). The function of a VSC is based on a fully controllable voltage source matching the system voltage in phase and frequency and with amplitude which can be controlled continuously and rapidly so as to be used as the tool for reactive power control.

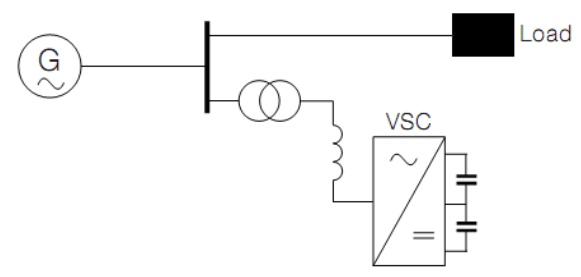

Fig. 1: STATCOM connection principle

STATCOM can increase voltage stability in the grid, provide dynamic voltage support, enhance power quality or balance the system in case of unsymmetrical loads. This increases system availability as well as lines power transmission capability. The dynamic balancing of reactive power flow can minimize system losses caused by reactive power in transmission lines and maximize power factor in the grid. STATCOM can be represented as a voltage source with an impedance $Z$ that could inject active and reactive power to the point of the grid where it is connected.

The main goal of the following case study is to define the best location for the STATCOM compensator and to minimize active power losses in grid, using Particle Swarm Optimization algorithm.

We consider 14 nodes in a power system with two voltage levels: $400 \mathrm{kV}$ and $220 \mathrm{kV}$. The first five nodes are on $400 \mathrm{kV}$ and the others are on $220 \mathrm{kV}$. Node 1 is a slack bus. The different voltage levels are connected by three phase control transformers $400 / 231 \mathrm{kV}$ with tapchanger on the secondary side $\pm 11 \times 1.13 \%$ (Fig. 2 ).

The blue area is a generating/load area for the $400 \mathrm{kV}$ voltage level, the green area is a generating/load industrial area and the red area is a generating/load housing estate for the $220 \mathrm{kV}$ voltage level. 


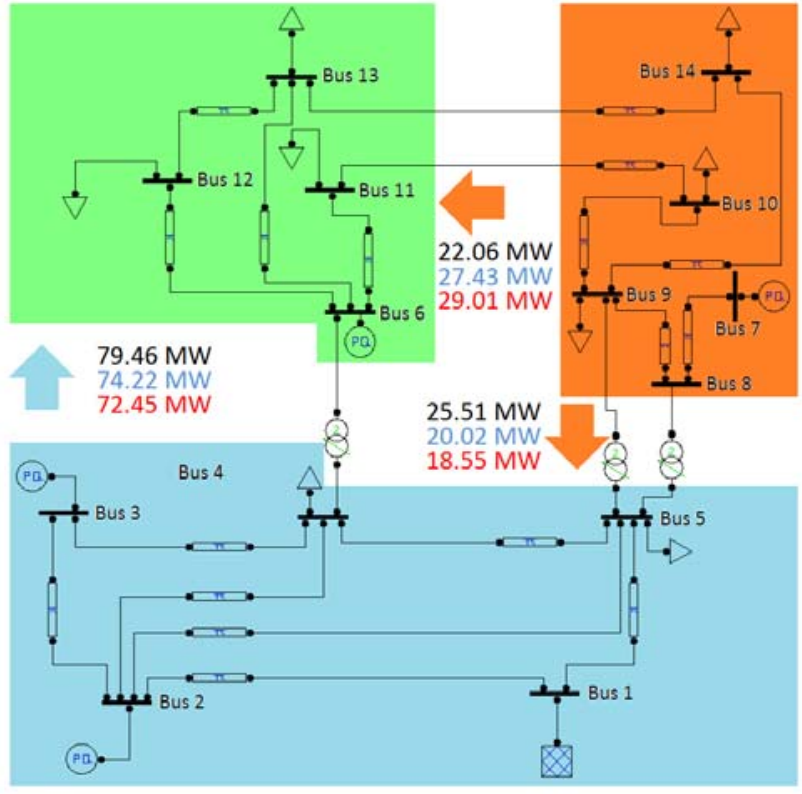

Fig. 2: Power system with 14 nodes

In the present research we formulate four main experiments:

1) Calculation of the network operating parameters without optimization.

2) Calculation of the network operating parameters after optimization - optimization was performed in order to reduce total active power losses in the system without and with using STATCOM.

3) Simulation of generator sources outages: gradually calculated cases with and without using STATCOM when sources outages were assumed and it was assumed that the outage is just in only one source in each of these cases. We did not consider the outage in the node 1 because this node is a balancing node. In all cases, the optimization was performed in order to keep all operational restrictions under permitted deviations while reducing the total active power losses in the network.

4) Simulation of the line disconnection between the nodes 8 and 9 was considered because this line is the second most overloaded line for the voltage level $220 \mathrm{kV}$ (most overloaded line for the level $220 \mathrm{kV}$ is the line between nodes 7 and 8 but the disconnection of that line caused a similar state as it was mentioned in case 3 , i.e. disconnection of the source at node 7). The objective was to keep any operational restrictions under permitted deviations while reducing the total active power losses in the network

\section{Simulation results}

The control variables are reactive powers on generators and taps on tap-changing transformers for cases without STATCOM. The reactive power generated/consumed by STATCOM is a control variable in cases with STATCOM. All simulations were performed in the program MATLAB $^{\text {TM }}$ using the Particle Swarm Optimization method.
We consider the following operational restrictions in all calculations:

1) Maximum voltage permissible deviations in the nodes: $5 \%$ for both voltage levels.

2) Maximum / minimum possible reactive power supplied by the generators: the generators are capable to take \pm 50 MVAr compared to the standard values presented in Tab. I. Positive values represent the active power generation and capacitive mode, negative values active power consumption and inductive mode.

3) Maximum / minimum values set by tap transformers: the transformer control range is from 202.3 to $241.4 \mathrm{kV}$. Since this method does not provide a continuous change of controlled voltage, it always chooses the nearest possible value of the adjustable transformer.

4) Thermal constraints of all transmission lines: the $400 \mathrm{kV}$ lines have maximum permissible current $2000 \mathrm{~A}, 220 \mathrm{kV}$ lines have maximum permissible current of $860 \mathrm{~A}$.

5) Maximum / minimum possible supplied / consumed reactive power using STATCOM: \pm 100 MVAr.

Table I - Active and reactive powers generated / absorbed at nodes

\begin{tabular}{|c|c|c|}
\hline Nodes & $\begin{array}{c}\text { Active power } \\
\text { (MW) }\end{array}$ & $\begin{array}{c}\text { Reactive power } \\
\text { (MVAr) }\end{array}$ \\
\hline 1 & \multicolumn{2}{|c|}{ Slack bus } \\
\hline 2 & 200 & 50 \\
\hline 3 & 200 & 50 \\
\hline 4 & -200 & -100 \\
\hline 5 & -200 & -100 \\
\hline 6 & 200 & 50 \\
\hline 7 & 200 & 50 \\
\hline 8 & 0 & 0 \\
\hline 9 & -50 & -25 \\
\hline 10 & -50 & -25 \\
\hline 11 & -100 & -50 \\
\hline 12 & -100 & -50 \\
\hline 13 & -100 & -50 \\
\hline 14 & -50 & -25 \\
\hline
\end{tabular}

We performed three types of experiments:

Experiment 1 - In this case we did not use any optimization technique and STATCOM was controlled to achieve minimum active power losses. Total active power losses were 9.09 MW. Simulation results for this case are represented by black colour in Fig. 3. As shown, voltages are out of permissible values.

Experiment 2 - In this case we applied the optimization technique to achieve minimum active power losses in considered network. We performed two simulations with and without STATCOM. Simulation results for these two states are shown in Figs. 3, 4. Blue colour represents the 
state after the optimization without STATCOM, red colour represents state after the optimization with STATCOM. Total active power losses were 8.51 MW for the state without STATCOM and 7.81 for state with STATCOM.

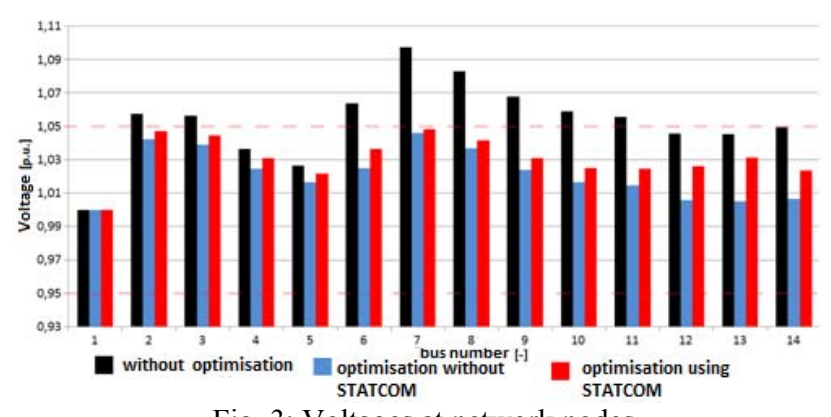

Fig. 3: Voltages at network nodes

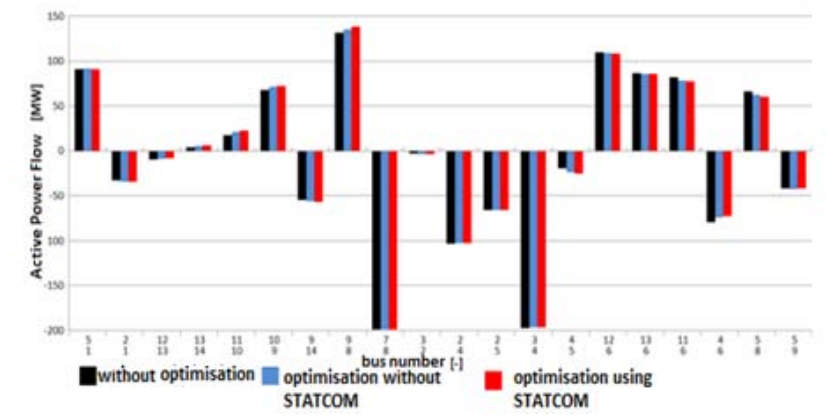

Fig. 4: Active power flow in all lines

Experiment 3 - In this case we considered generating sources outages (cases 2 to 5):

Case 1: Optimization (total without switching off) - this case represents simulation results captured in the experiment 2. Next four optimization processes were performed to achieve minimum active power losses without (grey colour) and with STATCOM (orange colour) in cases when we consider a generating source outage.

Case 2: Optimization (switch off generator 2)

Case 3: Optimization (switch off generator 3)

Case 4: Optimization (switch off generator 6)

Case 5: Optimization (switch off generator 7)

Fig. 5 and Table II show results of the experiment 3 described above, for the states with and without STATCOM. Table II shows the bus number where STATCOM was connected and the amount of reactive power that STATCOM supplied / absorbed from network.

Table II - Simulation results for all five cases

\begin{tabular}{|c|c|c|c|c|}
\hline \multirow[t]{2}{*}{ Case } & \multicolumn{2}{|c|}{ Active power losses [MW] } & \multirow{2}{*}{$\begin{array}{c}\text { Bus } \\
\text { number } \\
{[-]}\end{array}$} & \multirow{2}{*}{$\begin{array}{c}\text { Reactive } \\
\text { power } \\
{[\mathrm{MVAr}]}\end{array}$} \\
\hline & $\begin{array}{c}\text { without } \\
\text { STATCOM }\end{array}$ & $\begin{array}{c}\text { with } \\
\text { STATCOM }\end{array}$ & & \\
\hline 1 & 8,51 & 7,81 & 13 & 93,79 \\
\hline 2 & 8,65 & 7,76 & 2 & $-99,99$ \\
\hline 3 & 8,48 & 7,94 & 2 & $-99,99$ \\
\hline 4 & 17,97 & 15,93 & 12 & 99,93 \\
\hline 5 & 8,94 & 8,60 & 13 & 62,35 \\
\hline
\end{tabular}

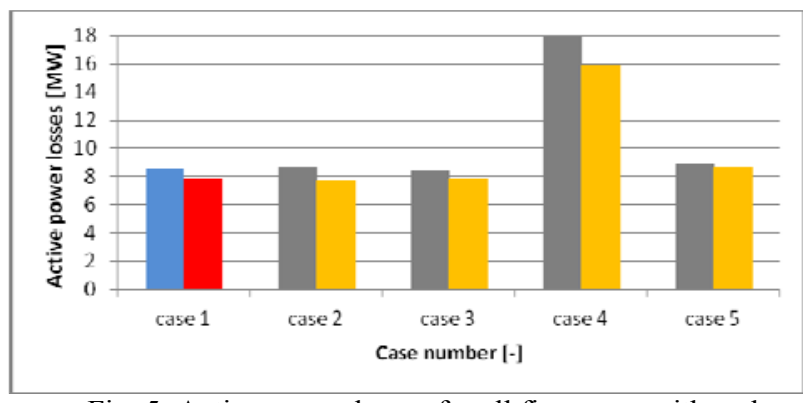

Fig. 5: Active power losses for all five cases with and without STATCOM

Experiment 4 - in this case we turn off the line between the nodes 8 and 9 . In the first case the simulation was performed without STATCOM (green color). In the second case STATCOM is connected (purple color).

As we can see in Fig. 6 it is possible to achieve lower active power losses with STATCOM in comparison with the case without STATCOM. STATCOM was placed at the node 13 and supplied the reactive power 87.589 MVAr. The voltage profile is shown for both states in Fig. 7 and the changes of the active power flow in all lines for both states are presented in Fig. 8.

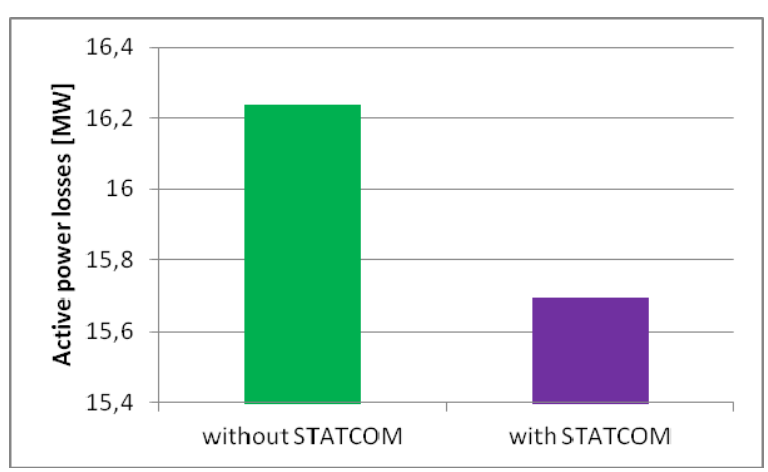

Fig. 6: Active power losses (line 8-9 is switched off)

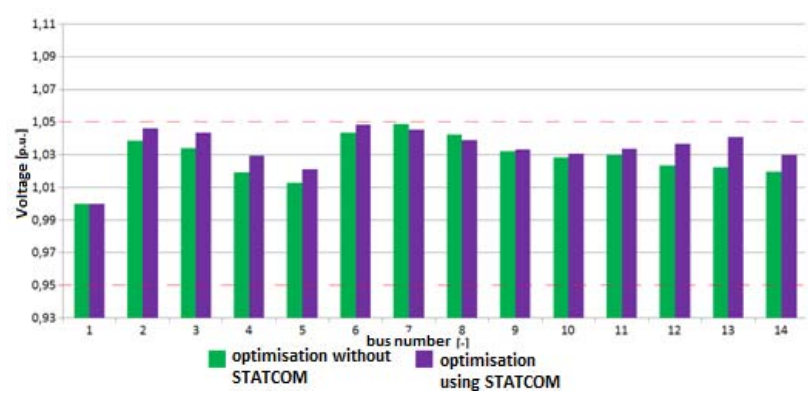

Fig. 7: Voltage profile (line $8-9$ is switched off)

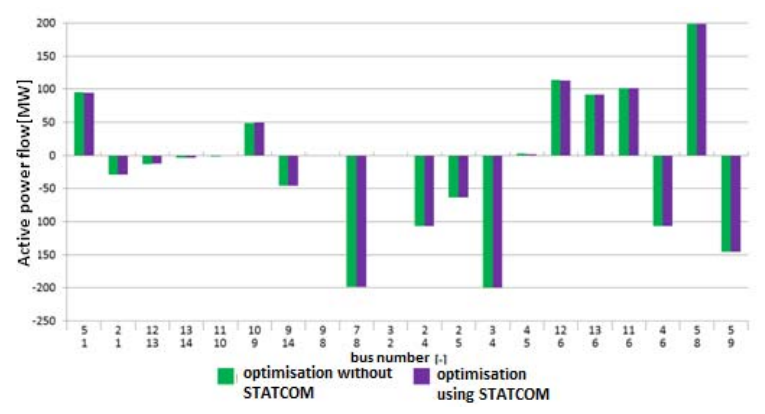

Fig. 8: Active power flow in all lines (line 8-9 is switched off) 


\section{Conclusions}

This paper describes theoretical and practical applications of FACTS devices such as STATCOM for voltage control and active power losses optimization. The idea and development with applying STATCOM for the optimization is presented.

STATCOM provides an improvement in power quality and active power consumption stabilisation. This effect could be used in applications where a variable load voltage should be compensated. It would result in a power stability improvement and decrease a risk of critical events caused by those sources. Using STATCOM, we are able to control the voltage at the node to which this device is connected and at the same time it is possible to reduce active power losses.

The shown simulation provides information for STATCOM design and placement in power grids. Applying Particle Swarm Optimization showed the potentials to use this method in power grids to improve their operation and selected criteria.

\section{Acknowledgement}

This paper was supported by the Technology Agency of the Czech Republic (TA ČR), grant No. TA03020095: The Reverse Effects Minimization of Non-linear and Dynamic Loads to the Supplying Grid.

\section{References}

[1] Anderson, P. M. Power System Control and Stability: Revised printing. New York: IEEE Press, 1993, 464 p. ISBN 07-803-1029-2.H. Song, K. Nam: "Dual current control scheme for PWM converter under unbalanced input voltage conditions" IEEE transactions on industrial electronics, vol. 46, No. 5, October 1999.

[2] Kusko, A., Thomson, M.: Power Quality in Electrical Systems. New York, McGraw-Hill, 2007, ISBN 978007-1470-759.

[3] Acha, E., Fuerte-Esquivel, C. R., Ambriz-Perez, H., Angeles-Camacho, C.: FACTS: Modeling and
Simulation in Power Networks. England, J. Wiley \& Sons, Ltd., 2004, ISBN 0-470-85271-2.

[4] D. Shirmohammadi, B. Wollenberg, A. Vojdani, P.Sandrin, M. Pereira, F. Rahimi, T. Schneider and B.Stott, "Transmission dispatch and congestion management in the emerging energy market structures", IEEE Transactions Power Systems., vol. 13, no. 4, pp.1466-1474, Nov. 1998.

[5] Acha, E. Power electronic control in electrical systems: short-circuit load flow and harmonics. Boston: Newnes, 2002, xii, 443 p. ISBN 07-5065126-1.

[6] Ter-Gazarian, A. Energy Storage for Power Systems. London: Lightning Source UK Ltd, 2008. 232 p.

[7] Das, J. Power system analysis: short-circuit load flow and harmonics. New York: Marcel Dekker, c2002, xiv, 850 p. ISBN 08-247-0737-0.

[8] E. N. Azadani, S. H.Hosseinian, P. Hasanpor, "Optimal placement of multiple STATCOM for voltage stability margin enhancement using particle swarm optimization", Journal Electrical Engineering, Springer, Vol. 90, Issue 7, 2008, pp. 503-510.

[9] N. Mancer, B. Mahdad, K. Srairi, "MultiObjective Optimal Reactive Power Flow Based STATCOM Using Three Variant of PSO", International Journal of Energy Engineering 2012, 2(2), pp. 1-7.

[10] Y. del Valle, J. C. Hernandez, G. Venayagamoorthy, R. G. Harley, "Multiple STATCOM allocation and sizing using particle swarm optimization" ,Proc. IEEE PES Power Systems Conf. Expo, 2006, pp. $1884-1891$.

[11] Y. del Valle, J. Hernandez, G. Venayagamoorthy, R. Harley, "Optimal STATCOM sizing and placement using particle swarm optimization", Proc. IEEE PES Transm. and Distrib. Conf. Expo-TDC'06, Latin America, 2006, pp.1-6.

[12] R. Sirkami, A. Mohamed, H. Shareef,“Optimal Placement and Sizing of Shunt FACTS Device in Power System Using Heurestic Optimization Techniques: a Comprehensive Survey“, PRZEGLĄD ELEKTROTECHNICZNY (Electrical Review), ISSN 0033-2097, R. 88, NR 10b/2012, pp. 341-335 